\title{
Non-Instantaneous Deterioration Inventory Model with Inflation and Stock-Dependent Demand
}

\author{
Aditya Sharma \\ B.Tech (ECE) Student \\ B.K. Birla Institute of \\ Engineering \&Technology Pilani, \\ Rajasthan (India)
}

\author{
Kumar Karan Gupta \\ B.Tech(ECE) Student \\ B.K. Birla Institute of \\ Engineering \&Technology Pilani, \\ Rajasthan (India)
}

\author{
A K Malik \\ Department of Mathematics \\ B.K. Birla Institute of \\ Engineering \&Technology Pilani, \\ Rajasthan (India)
}

\begin{abstract}
In this paper, an inventory model for an item is presented with inflation and stock dependent demand under non-instantaneous deterioration without allowing shortages. In real life conditions, freshness and quality ofsome products can be maintaining Here in this inventory model we assume that some products maintain originality for some time. The necessary and sufficient conditions are used to find the optimal solutions and the corresponding maximum profits for the different value sets of the given numerical data with sensitivity analyses and presented graphically.
\end{abstract}

\section{Keywords}

Non-instantaneous deterioration, Inflation, Inventory, purchasing cost, Sales revenue cost, Stock-dependent demand.

\section{INTRODUCTION}

Inflation plays an important role in the optimal order policy and influences the demand of certain products. Now a days it is observed that in the supermarket, display of the consumer goods in large quantities attracts more customers and generates higher demand. As a result, the effect of inflation and stock dependent demand cannot be ignored for determining the optimal inventory policy. Effect of inflation and stock dependent demand is also well established in inventory problems. FirstBuzacott (1975)discussed the inflation subject to different types of pricing policies.Gurnani (1983) developed economic analysis of inventory systems.FirstGupta and Vrat (1986)discussed the inventory models for stock-dependent consumption rate.

Hariga and M. Ben-daya (1996) presented an optimal timevarying lot sizing inventory models under inflationary conditions.Abad (2003)investigated the inventory models of this type of item. Chang (2004)discussed an inventory model by taking into account the inflation and finite time horizon with large quantity of purchase orders. Yang (2004)presented an inventory model with different pricing policies.Jaggi et al. (2006)developed an inventory model in which units are deteriorating at constant rate and demand rate is increasing exponentially due to inflation over a finite planning horizon using discount cash flow approach. Soni and Shah (2008) discussed the optimal ordering policy for an inventory model with stock-dependent demand under progressive payment scheme.

Most recently, Chang et al. (2010) developed an optimal replenishment policy for non-instantaneous deteriorating items with stock-dependent demand.Sana, S.S., (2012) developed an EOQ model for perishable items with stock-dependent demand.

This paper deals with an inventory model for non-instantaneous deteriorating items with inflation and stock-dependent demand.
Considering the realistic conditions, the problem of finding the optimal replenishment policy for non-instantaneous deteriorating items with inflation and stock-dependent demand is considered in this study. The necessary and sufficient conditions of the existence and uniqueness of the optimal solution are given. A numerical example, graphical illustration and sensitivity analysis are used to illustrate the model.

\section{NOTATION AND ASSUMPTIONS}

The following assumptions and notations are used in this paper: $D(t)=a+b Q(t)$ Demand rate at time $\mathrm{t}$, Where $\mathrm{a}, \mathrm{b}$ are positive constants and $\mathrm{Q}(\mathrm{t})$ is the inventory level at time $\mathrm{t}$.

$t_{1}$ Length of fresh product time

$\alpha$ Deterioration rate

A Ordering cost per order

$\mathrm{C}_{\mathrm{h}}$ Inventory holding cost per unit time

$\mathrm{C}_{\mathrm{p}}$ Purchasing cost per unit

$\mathrm{C}_{\mathrm{d}}$ Deteriorating cost per unit

$\mathrm{C}_{\mathrm{s}}$ Sales revenue cost per unit

$r$ Discount rate, representing the time value of money

$i$ Inflation rate

$\mathrm{R}$ Net discount rate of inflation; $\mathrm{R}=r-i$

$\mathrm{Q}_{1}$ Inventory level at time $\left[0, \mathrm{t}_{1}\right]$ in which the product has no deterioration.

$\mathrm{Q}_{2}$ Inventory level at time $\left[\mathrm{t}_{1}, \mathrm{t}_{2}\right]$ in which the product has deterioration.

TPTotal present value of profit per unit time of inventory system.

\section{MATHEMATICAL MODEL}

The inventory levels are governed by the following differential equations:

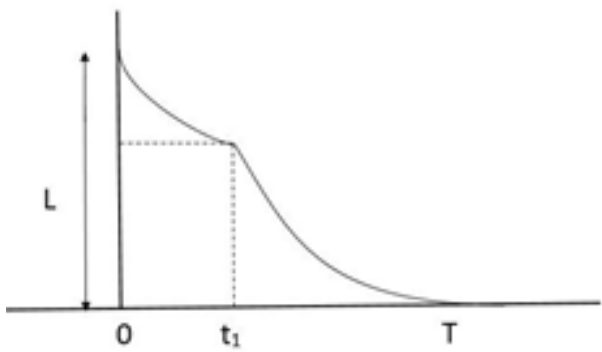

Fig 1: Inventory Model 


$$
\begin{aligned}
& \frac{d Q_{1}(t)}{d t}=-\left[a+b I_{1}(t)\right] \quad 0 \leq \mathrm{t} \leq \mathrm{t}_{1} \ldots(1) \\
& \frac{d Q_{2}(t)}{d t}+\alpha I_{2}(t)=-\left[a+b I_{2}(t)\right]^{\mathrm{t}_{1} \leq \mathrm{t} \leq \mathrm{T} \ldots}
\end{aligned}
$$

withtheboundaryconditions $Q_{1}(0)=L, Q_{2}(T)=0$

respectively. Solving these differential equations, we get the inventory level as follows:

$$
\begin{aligned}
& Q_{1}(t)=\frac{a}{b}\left(e^{-b t}-1\right)+L e^{-b t}, \quad 0 \leq \mathrm{t} \leq \mathrm{t}_{1} \\
& Q_{2}(t)=\frac{a}{b+\alpha}\left(e^{(b+\alpha)(T-t)}-1\right), \quad \mathrm{t}_{1} \leq \mathrm{t} \leq \mathrm{T} .
\end{aligned}
$$

Considering continuity of $\mathrm{Q}(\mathrm{t})$ at $\mathrm{t}=\mathrm{t}_{1}$, it follows from Equations (3) and (4) that $Q_{1}\left(t_{1}\right)=Q_{2}\left(t_{1}\right)$

$$
\Rightarrow L=\frac{a}{b+\alpha}\left(e^{(b+\alpha) t_{2}}-1\right) e^{b t_{1}}-\frac{a}{b}\left(1-e^{b t_{1}}\right) .
$$

Now the total present value of profit per cycle consists of the following elements:

1) Ordering cost per cycle is $\mathrm{OC}=\mathrm{A}$.

2)Holding cost per cycle is given by

$$
\begin{aligned}
& H C=C_{h}\left(\int_{0}^{t_{1}} e^{-R t} Q_{1}(t) d t+\int_{t_{1}}^{T} e^{-R t} Q_{2}(t) d t\right) \\
& =C_{h}\left[\frac{a e^{-R t_{1}}\left(R+b-\mathrm{Re}^{-b t_{1}}\right)-a b}{b R(R+b)}+\frac{L}{R+b}\left(1-e^{-(R+b) t_{1}}\right)\right. \\
& +\frac{a}{b+\alpha}\left\{\frac{(b+\alpha) e^{-R T}+e^{-R t_{1}}\left(\operatorname{Re}^{(b+\alpha) t_{2}}-R-b-\alpha\right)}{R(b+\alpha+R)}\right\} \ldots(7)
\end{aligned}
$$

3) Deterioration cost per cycle is given by

$$
\begin{aligned}
& D C=C_{d} \int_{t_{1}}^{T} \alpha e^{-R t} Q_{2}(t) d t \\
& =\alpha C_{d}\left[\frac{a}{b+\alpha}\left\{\frac{(b+\alpha) e^{-R T}+e^{-R_{t_{1}}}\left(\operatorname{Re}^{(b+\alpha) t_{2}}-R-b-\alpha\right)}{R(b+\alpha+R)}\right\}\right]
\end{aligned}
$$

4) Purchasing cost per cycle is given by

$$
P C=C_{p} \times L=C_{p}\left[\frac{a}{b+\alpha}\left(e^{(b+\alpha) t_{2}}-1\right) e^{b t_{1}}-\frac{a}{b}\left(1-e^{b t_{1}}\right)\right] \ldots
$$

5) Sales Revenue cost per cycle is given by

$$
\begin{aligned}
& S R C=C_{s} \int_{0}^{T} e^{-R t} D(t) d t \\
&= C_{S}\left[\frac{a}{R}\left(1-e^{-R T}\right)+\frac{a e^{-R t_{1}}\left(R+b-\mathrm{Re}^{-b t_{1}}\right)-a b}{R(R+b)}\right. \\
&+ \frac{L b}{R+b}\left(1-e^{-(R+b) t_{1}}\right) \\
&\left.+\left(\frac{a b}{b+\alpha}\right)\left(\frac{(b+\alpha) e^{-R T}+e^{-R t_{1}}\left(\operatorname{Re}^{(b+\alpha) t_{2}}-R-b-\alpha\right)}{R(b+\alpha+R)}\right)\right] \ldots(10)
\end{aligned}
$$

Thus the total present value of profit per cycle per unit time is given by

$$
T P=\frac{1}{T}[S R C-O C-H C-D C-P C] \cdots
$$

Substituting equations (6-10) in the above equation (11), we get

$$
\begin{aligned}
& T P=\frac{1}{T}\left[C _ { S } \left\{\frac{a}{R}\left(1-e^{-R T}\right)+\frac{a e^{-R t_{1}}\left(R+b-\mathrm{Re}^{-b t_{1}}\right)-a b}{R(R+b)}\right.\right. \\
& +\frac{L b}{R+b}\left(1-e^{-(R+b) t_{1}}\right) \\
& \left.+\left(\frac{a b}{b+\alpha}\right)\left(\frac{(b+\alpha) e^{-R T}+e^{-R t_{1}}\left(\operatorname{Re}^{(b+\alpha) t_{2}}-R-b-\alpha\right)}{R(b+\alpha+R)}\right)\right\} \\
& -A-C_{h}\left\{\frac{a e^{-R t_{1}}\left(R+b-\mathrm{Re}^{-b t_{1}}\right)-a b}{b R(R+b)}+\frac{L}{R+b}\left(1-e^{-(R+b) t_{1}}\right)\right. \\
& \left.+\frac{a}{b+\alpha}\left(\frac{(b+\alpha) e^{-R T}+e^{-R t_{1}}\left(\operatorname{Re}^{(b+\alpha) t_{2}}-R-b-\alpha\right)}{R(b+\alpha+R)}\right)\right\} \\
& -\alpha C_{d}\left\{\frac{a}{b+\alpha}\left(\frac{(b+\alpha) e^{-R T}+e^{-R t_{1}}\left(\operatorname{Re}^{(b+\alpha) t_{2}}-R-b-\alpha\right)}{R(b+\alpha+R)}\right)\right\} \\
& \left.\left.-C_{p}\left\{\frac{a}{b+\alpha}\left(e^{(b+\alpha) t_{2}}-1\right) e^{b t_{1}}-\frac{a}{b}\left(1-e^{b t_{1}}\right)\right\}\right](12)\right]
\end{aligned}
$$

The total present value of profit per unit time is maximumif $\frac{d T P}{d t_{2}}=0 \cdots(13)$

$$
\text { and } \frac{d^{2} T P}{d t_{2}^{2}}<0
$$

\section{SOLUTION ALGORITHM FOR PROPOSED MODEL}

Step.1. Input A, $C_{h}, C_{p}, C_{s}, C_{d}, \alpha, R, a, b, t_{1}$

Step.2. From equation(13) compute $t_{2}$ and from Relation (12) compute TP;

Step.3. Put the value of $t_{2}$ in equation (14) to check the optimal solution. If satisfied then go to stop otherwise go to step 1 for changing the parameters values.

\section{NUMERICAL EXAMPLE AND SENSITIVITY ANALYSIS}

To illustrate the above results, we consider the following example: $\mathrm{A}=500, \mathrm{R}=0.01, \mathrm{C}_{\mathrm{s}}=30$ per unit, $\mathrm{Cp}=15$ per unit, $\mathrm{C}_{\mathrm{h}}=0.50$ per unit, $\mathrm{C}_{\mathrm{d}}=0.2$ per unit, $\alpha=0.60, a=100$ and $b=0.5$ units. From Table 1, we observe that the system cost (TP) is Maximum when $\mathrm{t}_{1}=1 / 5$ and $\mathrm{t}_{2}=1.76$ (month).

As can be observed in the above study the sensitivity analysis of the parameters present in this inventory model, the total profit changes significantly with changes in the different demand values. 
Table 1. Variation of demand ' $a$ ' according to $t_{2}, L$ and TP

\begin{tabular}{|c|c|c|c|}
\hline & \multicolumn{3}{|c|}{ Demand part $a$} \\
\hline & 100 & 110 & 120 \\
\hline$t_{2}$ & 1.76 & 1.71 & 1.67 \\
\hline $\mathrm{L}$ & 618.2 & 638.4 & 657.8 \\
\hline $\mathrm{TP}$ & 1253.7 & 1404.9 & 1556.7 \\
\hline
\end{tabular}

If the demand rates $(a)$ increase, then the lower time $t_{2}$, the longer order quantity (L) and total profit (TP) increase.

Table 2. Variation of demand ' $b$ ' according to $t_{2}, L$ and TP

\begin{tabular}{|c|c|c|c|}
\hline & \multicolumn{3}{|c|}{ Demand part $b$} \\
\hline & 0.50 & 0.49 & 0.48 \\
\hline$t_{2}$ & 1.76 & 1.63 & 1.54 \\
\hline $\mathrm{L}$ & 618.2 & 520.4 & 454.6 \\
\hline TP & 1253.7 & 1220.4 & 1191.2 \\
\hline
\end{tabular}

If the demand rate $(b)$ increases, then the longer time $t_{2}$, the longer order quantity (L) and total profit (TP) increases.

Table 3. Variation of Deterioration rate $\alpha$ according to $t_{2}, L$ and TP

\begin{tabular}{|c|c|c|c|}
\hline & \multicolumn{3}{|c|}{ Deterioration rate $\alpha$} \\
\hline & 0.60 & 0.61 & 0.62 \\
\hline$t_{2}$ & 1.76 & 1.66 & 1.58 \\
\hline L & 618.2 & 549.9 & 498.7 \\
\hline TP & 1253.7 & 1231 & 1210.3 \\
\hline
\end{tabular}

If deterioration rate $(\alpha)$ increases, then the time $t_{2}$, order quantity (L) and total profit (TP) decreases.

Table 4. Variation of Sales revenue cost $C_{s}$ according to $\mathrm{t}_{2}, \mathrm{~L}$ and TP

\begin{tabular}{|c|c|c|c|}
\hline & \multicolumn{3}{|c|}{ Sales revenue cost $C_{s}$} \\
\hline & 28 & 29 & 30 \\
\hline$t_{2}$ & 1.26 & 1.44 & 1.76 \\
\hline $\mathrm{L}$ & 321.4 & 409.1 & 618.2 \\
\hline $\mathrm{TP}$ & $\mathbf{8 8 9 . 1}$ & $\mathbf{1 0 6 0 . 5}$ & 1253.7 \\
\hline
\end{tabular}

If the sales revenue cost $\left(\mathrm{C}_{\mathrm{s}}\right)$ increases, then the time $\mathrm{t}_{2}$, order quantity (L) and total profit (TP) increases.
Table 5. Variation of Purchasing cost $C p$ according to $t_{2}, L$ and TP

\begin{tabular}{|c|c|c|c|}
\hline & \multicolumn{3}{|c|}{ Purchasing cost $C p$} \\
\hline & 15 & 16 & 17 \\
\hline$t_{2}$ & 1.76 & 1.26 & 1.05 \\
\hline $\mathrm{L}$ & 618.2 & 321.8 & 238.2 \\
\hline TP & 1253.7 & $\mathbf{9 9 8 . 3}$ & 794.3 \\
\hline
\end{tabular}

If purchasing cost $\left(\mathrm{C}_{\mathrm{p}}\right)$ increase, then the time $t_{2}$, order quantity (L) and total profit (TP) decreases.

Table 6. Variation of Holding cost Chaccording to $t_{2}, L$ and TP

\begin{tabular}{|c|c|c|c|}
\hline & \multicolumn{3}{|c|}{ Holding cost Ch } \\
\hline & .40 & .50 & .60 \\
\hline$t_{2}$ & 1.87 & 1.76 & 1.67 \\
\hline L & 705.3 & 618.2 & 554.6 \\
\hline TP & 1277.6 & 1253.7 & 1234.1 \\
\hline
\end{tabular}

If the holding cost $\left(C_{h}\right)$ increase, then the time $t_{2}$, order quantity (L) and total profit (TP) decreases.

Table 7. Variation of Ordering cost $A$ according to $t_{2}, L$ and TP

\begin{tabular}{|c|c|c|c|}
\hline & \multicolumn{3}{|c|}{ Ordering cost $A$} \\
\hline & 500 & 600 & 700 \\
\hline$t_{2}$ & 1.76 & 1.86 & 1.95 \\
\hline L & 618.2 & 698.4 & 775.4 \\
\hline TP & 1253.7 & $\mathbf{1 2 0 4 . 0}$ & 1156.5 \\
\hline
\end{tabular}

If the ordering cost (A) increases then it is quite natural that the total profit (TP) for this purpose decreases.

Table 8. Variation of Inflation rate $R$ according to $t_{2}, L$ and TP

\begin{tabular}{|c|c|c|c|}
\hline & \multicolumn{3}{|c|}{ Inflation rateR } \\
\hline & .010 & .015 & .020 \\
\hline$t_{2}$ & 1.76 & 1.69 & 1.62 \\
\hline L & 618.2 & 563.5 & 519.3 \\
\hline TP & 1253.7 & 1231.3 & 1210.4 \\
\hline
\end{tabular}

If theinflation rate $(\mathrm{R})$ increases then it is quite natural that the total profit (TP) for this purpose decreases.

The following graphs show the relation between total profit(TP) and time period $t_{1}$ and $t_{2}$. 


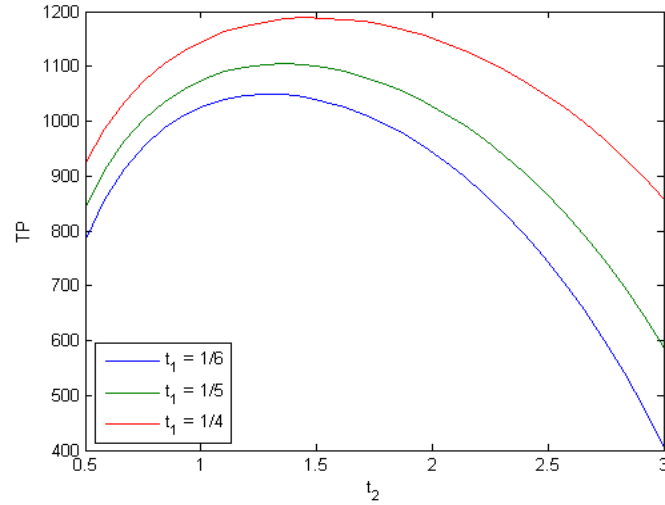

Fig 2: Total Profit TP v/s $t_{2}$ for different $t_{1}$ values

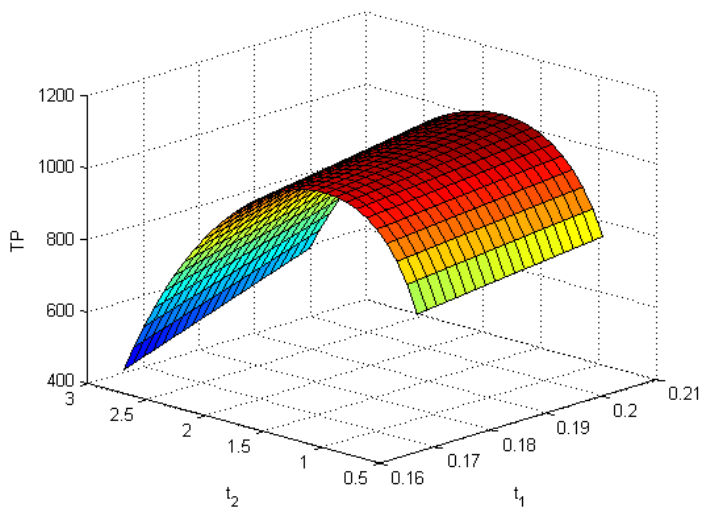

Fig 3: 3D view of Total Profit TP v/s $t_{2}$ for different $t_{1}$ values

\section{CONCLUSION}

This study introduces the concept of an inventory control system against the non-instantaneous deteriorating items withinflationwithout allowing shortages. Here in this paper we have used a numerical example to demonstrate sensitivity analysis and to get the optimal solution. A possible future research direction is the study of an inventory model for production rate, inflation, shortages, partial backlogging, two warehouse,permissible delay in payments, advance payment and supply-chain models etc.

\section{ACKNOWLEDGMENTS}

The authorsare indebted to Dr. P.S. Bhatnagar, Director of B.K. Birla Institute of Engineering \& Technology Pilani, Rajasthan (India)for his most valuable advice andencouragement.We are also thankful to Prof. S.B. Dandin (Dean), Prof. L. Solanki (Dean), Prof. A.P. Girdhar and Prof. S.R. Yadav from B.K. Birla Institute of Engineering \& Technology, Pilani, Rajasthan (India) for their encouragement and whole hearted cooperation.

\section{REFERENCES}

[1] J.A. Buzacott, (1975). Economic order quantities with inflation, Operation Research 26, 553-558.

[2] C. Gurnani, (1983). Economic Analysis of Inventory systems, Int. J. Prod. Res. 21, 261-277.

[3] Gupta, R., Vrat, P., (1986). Inventory model with multiitems under constraint systems for stock dependent consumption rate. Operations Research 24, 41-42.
[4] M. Hariga, M. Ben-daya, (1996). Optimal time-varying lot sizing models under inflationary conditions, EuropeanJournal ofOperation Research. 89, 313-325.

[5] P.L. Abad, (2003). Optimal Pricing and Lot-Sizing Under Conditions of Perish ability, Finite Production and Partial Backordering and Lost Sale, Eur. J. Oper. Res. 144, 677685

[6] C.T. Chang, (2004). An EOQ model with deteriorating items under inflation when supplier credits linked to ordering quantity, International Journal of Production Economics 88, 307-316.

[7] P.C. Yang, (2004). Pricing strategy for deteriorating items using quantity discount when demand is price sensitive, European Journal of Operations Research 157, 389-397.

[8] C.K. Jaggi, K.K. Aggarwal, S.K. Goyal, (2006). Optimal Order Policy for Deteriorating Items with Inflation Induced Demand, International Journal of Production Economics 103, 707-714.

[9] Soni H, Shah NH (2008). Optimal ordering policy for stock-dependent demand under progressive payment scheme. European Journal of Operational Research 184:91-10.

[10] Chun-Tao Chang, Jinn-TsairTeng, Suresh Kumar Goyal (2010). Optimal replenishment policies for noninstantaneous deteriorating items with stock-dependent demand, International Journal of Production Economics, Volume 123, 62-68.

[11] Sana, S.S., (2012). An EOQ model for perishable item with stock-dependent demand and price discount rate. American Journal of Mathematical and Management Sciences.

\section{AUTHOR'S PROFILE}

Mr. Aditya Sharma is pursuing B.Techin Electronics and communication at B. K. Birla Institute of Engineering \& Technology, Pilani (Rajasthan).His area of interest isembedded system, inventory control and software designing. He visited the Bangkok University, Bangkok for research and project on Visual Light Communication and developed software for GDSII.

Mr. Kumar Karan Gupta is pursuing B. Techin Electronics and communication at B. K. Birla Institute of Engineering \& Technology, Pilani (Rajasthan). His area of interest is Embedded system and Optimizations Operations Research and Reliability theory. He visited IUT Angouleme, France for research and project work on Microcontrollers and Voltage Controlled Oscilloscope.

Dr. A. K. Malik, Assistant Professor of Mathematics in B. K. Birla Institute of Engineering \& Technology, Pilani (Rajasthan), has experience of eight years in academics and research. His area of interest is Inventory control, soft computing and Supply Chain Management. He has published more than twenty research papers in reputed national and international.He is reviewer/editorial board member of many national and international journals like as "OPSEARCH" and "International Journal of Soft Computing and Engineering"etc. 